Journal of

Memory and

Language

www.elsevier.com/locate/jml

\title{
The independence of combinatory semantic processing: Evidence from event-related potentials
}

\author{
Albert Kim*, Lee Osterhout \\ Department of Psychology, University of Washington, USA
}

Received 13 April 2004; revision received 6 October 2004

Available online 10 December 2004

\begin{abstract}
We recorded event-related brain potentials (ERPs) while participants read sentences, some of which contained an anomalous word. In the critical sentences (e.g., The meal was devouring...), the syntactic cues unambiguously signaled an Agent interpretation of the subject noun, whereas the semantic cues supported a Theme interpretation. An Agent interpretation would render the main verb semantically anomalous (as meals do not devour things). Conversely, the Theme interpretation would render the main verb syntactically anomalous (as the -ED form, not the -ING form, is syntactically appropriate for this interpretation). We report that the main verbs in such sentences elicit the P600 effect associated with syntactic anomalies, rather than the N400 effect associated with semantic anomalies. We conclude that, at least under certain conditions, semantic information is "in control" of how words are combined during sentence processing.
\end{abstract}

(c) 2004 Elsevier Inc. All rights reserved.

Keywords: Syntax; Semantics; Thematic roles; ERPs; Sentence processing; N400; P600

Language comprehension involves combining words into larger representational units, such as phrases and clauses. Psycholinguistic investigation of such combinatory processing has focused heavily on the construction of syntactic representations, which provide a structural basis for semantic and pragmatic representations (e.g., Altmann \& Steedman, 1988; Clifton et al., 2003; Osterhout, Holcomb, \& Swinney, 1994; Rayner, Carlson, \& Frazier, 1983; Trueswell, Tanenhaus, \& Garnsey, 1994; Tanenhaus, Spivey-Knowlton, Eberhard, \& Sedivy, 1995). Within this syntacto-centric view, accurate syntactic analysis of the linguistic input is essential to successful interpretation. Contrary to such models, we

\footnotetext{
* Corresponding author. Fax: +1 2066853157.

E-mail address: alkim@u.washington.edu (A. Kim).
}

report here that under certain syntactically unambiguous conditions the semantic relationships between words in a sentence are determined independently of, and even guide, the syntactic analysis of that sentence.

Syntacto-centric models have been deeply influenced by the issue of syntactic ambiguity and how it is resolved. It is well established that syntactic ambiguity challenges language comprehenders, leading to systematic errors of comprehension known as garden path effects (cf. Altmann, 1998). For instance, readers of temporarily ambiguous sentences like The defendant examined by the lawyer was lying often interpret examined as the sentence's main verb when it is actually embedded in a relative clause. Processing errors are indicated by difficulty reading by the lawyer..., which disambiguates the sentence (Clifton et al., 2003; Ferreira \& Clifton, 1986; Rayner et al., 1983; Trueswell et al., 1994). 
Two influential families of models have developed around the study of garden path effects. Syntax-first models argue that a modular syntactic processing system precedes and guides semantic interpretation (e.g., Ferreira \& Clifton, 1986, 1996). The syntactic system's initial response to syntactic ambiguity is to choose a single syntactic analysis based on preferences about grammatical structures. This initial analysis is then semantically evaluated and sometimes revised. When grammatical preferences support the wrong analysis, garden-path effects are predicted. Constraint-based models propose that syntactic ambiguities trigger the parallel activation of all analyses consistent with the grammar (e.g., MacDonald, Pearlmutter, \& Seidenberg, 1994; Trueswell \& Tanenhaus, 1994). A single analysis is selected through the coordination of multiple types of knowledge, including semantic knowledge and statistical knowledge about the structural biases of words. When evidence accumulates in favor of the wrong analysis, garden-path errors are predicted.

Despite fundamental differences, these models share a characterization of combinatory language processing as a series of choices about syntactic analysis. Furthermore, both models assume that syntactic cues, when unambiguous, will control the initial combinatory analysis of linguistic input. This assumption is fundamental to the logic of garden path experiments, in which syntactically unambiguous cues in baseline sentences are expected to cause immediate commitment to a single combinatory analysis. ${ }^{1}$ Within this view, semantic factors may influence combinatory decisions when syntactic cues are ambiguous, but do not exert a controlling influence when syntactic cues are unambiguous.

Some recent findings seem outside the explanatory scope of the standard syntacto-centric paradigm. For example, head-mounted eye-tracking studies show that participants hearing a transitive verb in a simple sentence can begin eye-movements to plausible post-verbal objects before hearing the referring noun (Altmann \& Kamide, 1999; Kamide, Altmann, \& Haywood, 2003). One interpretation of such effects is that world knowledge about events and their participants can drive interpretation independently of the syntactic dependencies within the linguistic input (i.e., between the verb and its direct object). Other findings (Ferreira, 2003) suggest that semantic information can determine interpretation even when it directly conflicts with unambiguous syntactic cues. When plausible sentences (e.g., The mouse ate the cheese) were reversed to form implausible sentences

\footnotetext{
1 This assumption also applies to the "disambiguating" region of temporarily ambiguous sentences. Comprehenders encounter syntactically unambiguous cues in this region, and it is assumed that such cues will force them to compute the syntactically licensed interpretation.
}

(e.g., The cheese ate the mouse), participants tended to name the wrong entity as "do-er" or "acted-on," as if coercing the reversed sentences to be plausible (see also Caplan, Hildebrandt, \& Waters, 1994; Herriot, 1969; Saffran, Schwartz, \& Linebarger, 1998; Slobin, 1966). However, these demonstrations of semantic influences on sentence processing are not without complications. "Anticipatory" semantic interpretation, evidenced by eye-movements, might not be truly independent of syntactic control; rather predictive interpretation may be controlled by predictive syntactic structure. Participants hearing a verb might activate verb-specific syntactic knowledge that predicts a post-verbal argument and interpret the visual display accordingly (Kamide et al., 2003). The processing implications of Ferreira's (2003) and related results are uncertain, due to the use of post-sentence ruminative responses, which do not indicate whether semantic influences reflect the listeners' initial responses to the input or some later aspect of processing.

Here we used scalp-recorded event-related potentials (ERPs) to contrast the syntacto-centric view with a view that attributes greater independence to combinatory semantic processing. ERPs provide continuous measurement of the brain's electrical activity with high temporal resolution. Importantly, ERPs also respond differently to syntactic and semantic aspects of sentence processing (cf. Osterhout, McLaughlin, Kim, Greenwald, \& Inoue, 2004). Semantically anomalous words elicit a negative wave that peaks approximately $400 \mathrm{~ms}$ after word onset (the $N 400$ effect; Kutas \& Hillyard, 1980, 1984; Osterhout \& Nicol, 1999). By contrast, syntactically anomalous words elicit a large positive wave that onsets approximately $500 \mathrm{~ms}$ after the word appears and persists for at least half a second (the P600 effect) (Hagoort, Brown, \& Groothusen, 1993; Osterhout, 1997; Osterhout \& Holcomb, 1992, 1993; Osterhout, McKinnon, Bersick, \& Corey, 1995; Osterhout et al., 1996; Osterhout \& Nicol, 1999). ${ }^{2}$ These language-related ERP effects are highly reproducible and generalize across various sub-classes of violation (P600 effects are elicited by violations involving phrase structure, agreement, verb subcategorization, and constituent-movement), types of languages (including word-order languages such as English, Dutch, and French, and case-marked languages such as Italian and Japanese; Inoue \& Osterhout, 2004), and various methodological factors (including modality of the input,

\footnotetext{
${ }^{2}$ In some studies, syntactic violations have also elicited a negative wave over anterior regions of the scalp, with onsets ranging from 150 to $300 \mathrm{~ms}$ (Friederici, 1995; Neville, Nicol, Barss, Forster, \& Garrett, 1991; Osterhout \& Holcomb, 1992; Osterhout \& Mobley, 1995). In the study we describe here and related studies by Kolk, Chwilla, van Herten, and Oor (2003) and Kuperberg, Sitnikova, Caplan, and Holcomb (2003), no such effects were observed.
} 
rate of word presentation, stimuli comprised of isolated sentences or natural prose, and participants' task; McKinnon \& Osterhout, 1996; Osterhout \& Holcomb, 1993; Osterhout, McLaughlin, Allen, \& Inoue, 2002). ${ }^{3}$

Two recent studies have appeared to contradict the generalization that $\mathrm{N} 400$ and P600 effects correlate with semantic and syntactic violation, respectively (Kolk et al., 2003; Kuperberg et al., 2003). Kolk et al. (2003) presented Dutch sentences containing relative clauses such as De vos die op de stropers joeg... (The fox that hunted the poachers...). At the clause-final verb joeg (hunted), the syntactic cues unambiguously indicated that the fox is the Agent and the poachers are the Theme. Although this analysis is semantically implausible, the verb elicited a P600 effect rather than an N400 effect. Similarly, Kuperberg et al. (2003) report that the apparently semantically anomalous verbs in sentences such as For breakfast, the eggs would only eat... elicited a P600 effect. One possible explanation for these unexpected results is that, as proposed by Ferreira (2003), the processing system can (at least in some circumstances) pursue a semantically attractive interpretation even when it contradicts unambiguous syntactic cues. In both of these experiments, the stimulus sentences contained a verb and nouns that could be combined in a semantically plausible manner (e.g., the poachers hunt the fox; someone eats the eggs). Critically, however, this plausible interpretation is inconsistent with the syntactic structure of the sentence. In such situations, the semantic attraction of a particular interpretation might make an unambiguous, syntactically well-formed sentence appear to be syntactically anomalous. Such an account would be incompatible with standard syntacto-centric models.

We examined this possibility by recording brain responses to simple, syntactically unambiguous strings like The hearty meal was devouring.... The verb devouring is clearly anomalous. Less clear is what type of anomaly is

\footnotetext{
${ }^{3}$ Our claim that syntactic anomalies elicit a P600 effect is a simple restatement of empirical evidence and is not a theoretical claim about the cognitive process made manifest by the P600 effect. Because the correlation between the presentation of a syntactic anomaly and elicitation of the P600 is so strong (and likewise for the presentation of a semantic anomaly and the elicitation of the N400 effect), one can reasonably infer that if a sentence-embedded linguistic anomaly elicits a P600 effect, it was perceived to be syntactic in nature; whereas if it elicits an N400 effect, it was perceived to be semantic/pragmatic in nature. This logic accommodates reports that things other than violations of syntactic rules elicit P600-like effects, including the perceived syntactic anomaly resulting from a syntactic garden path effect (Osterhout et al., 1994) and the introduction of syntactic complexity (Kaan, Harris, Gibson, \& Holcomb, 2000). The logic furthermore holds even if P600 and N400 effects are not direct manifestations of syntactic and semantic processing, respectively.
}

manifested: devouring could be perceived as either syntactically or semantically anomalous. The nature of the anomaly depends on how the comprehender coordinates syntactic and semantic knowledge while interpreting the string. The syntactic cues unambiguously signal that the subject noun meal is the Agent of the verb devouring. Such an interpretation is semantically anomalous, as inanimate objects do not typically devour things. Therefore, models of syntactic ambiguity resolution predict that the verb devouring will be perceived to be semantically anomalous, and elicit an N400 effect.

By contrast, the semantic cues in the sentence suggest a different interpretation. While meal is an anomalous Agent for devouring, it is a highly plausible Theme. The "semantic attraction" to the Theme interpretation might be so compelling that it is pursued even though it contradicts the syntactic structure of the sentence. However, such an interpretation requires a passive -ED inflection at the verb (as in The hearty meal was devoured...), rather than -ING. Thus, at the verb, the syntactic cues become ill-formed to support this semantically attractive Theme interpretation. If the language processing system is driven by the semantic attractiveness of the Theme assignment, the verb devouring will be perceived to be syntactically anomalous, and hence elicit a P600 effect. That is, powerful semantic cues may cause a syntactically well-formed string to appear to be syntactically ill-formed.

\section{Experiment 1}

\section{Method}

\section{Participants}

Twenty-four undergraduate students (11 females) from the University of Washington participated in the experiment for course credit or cash. Participants ranged in age from 18 to $30($ mean $=19.7)$ years. All participants in this experiment and in Experiment 2 were right-handed native English speakers with normal or corrected-to-normal vision.

\section{Stimuli}

Ninety-six stimulus items were created, each in three forms, as exemplified by $1 \mathrm{a}-\mathrm{c}$. The full stimulus set is listed in the Appendix A. Each stimulus exemplar consisted of the following sequence: a noun phrase, an auxiliary verb sequence (e.g., was), a critical verb (e.g., devouring), and post-verbal material (e.g., the detective). In Violation stimuli (1a) the syntactic cues unambiguously signal an Agent interpretation of the initial noun phrase. The initial noun phrase was inanimate and was an anomalous Agent but highly plausible Theme for the critical verb, as determined by experimenter intuition. Two kinds of control stimuli were created, which 
were derived from Violation stimuli by altering either the syntactic or the semantic cues in order to provide a well-formed and plausible analog of the Violation stimuli. Passive Control stimuli (1b) were identical to Violation stimuli, up to and including the critical verb, except that the critical verb was inflected with -ED rather than -ING. This resulted in highly plausible passive sentences, with the initial noun phrase assigned to the Theme role of the critical verb. Active Control stimuli (1c) contained the same -ING inflected critical verb as Violation stimuli but began with an animate noun phrase, which was a plausible Agent and anomalous Theme for the critical verb, as determined by experimenter intuition. This resulted in highly plausible active-voice sentences, with the initial noun phrase assigned the Agent role of the critical verb.

1a. The hearty meal was devouring the kids.

1b. The hearty meal was devoured by the kids.

1c. The hungry boy was devouring the cookies.

\section{Violation}

Passive Control

Active Control

Within each stimulus triplet, the auxiliary verb sequence was held constant $(41 \%$ of the items used was or a morphological variant thereof, and the rest used has been or some variant thereof). The material following the critical verb was not necessarily constant within an item, as discussed below.

Violation stimulus exemplars were constructed with three different types of post-critical-verb continuations: by-phrase (e.g., .. .by the kids); noun phrase (e.g., ...the kids); verb phrase modifier (e.g., ...rapidly), in 33, 31, and 32 of the 96 items, respectively. This manipulation affected material after the critical word, and therefore did not directly affect the processing response on a given trial. Its purpose was twofold. First, it was intended to reduce the recognizability of our Violation condition. Second, since the type of continuation may suggest a particular interpretation of the string (by-phrase may suggest a syntactic violation, and noun phrase continuations may suggest a semantic violation), we wanted to eliminate regularities that might allow participants to learn to parse the strings in one particular way, either implicitly or explicitly.

Three stimulus lists were created using these materials. Each participant saw one of these lists. Each list contained 32 stimuli from each stimulus type. Each stimulus item occurred only once in each list. Stimulus items were rotated through condition assignments, such that each item occurred in a different stimulus type in each list. Each list also contained 107 filler stimuli. Of these, 27, 27, and 53 were semantically anomalous (e.g., "He quit smoking when his cloud asked him to."), syntactically anomalous (e.g., "Isaac swim in the municipal swim- ming pool every day."'), and well-formed and plausible (e.g., "The group of tourists hiked up the scenic trail."), respectively. Thus, each list contained 203 sentences in total. Fifty-eight percent were well-formed and $42 \%$ were anomalous. Stimuli were pseudo-randomly ordered, subject to the following constraints: (1) target stimuli were separated by at least one filler; (2) each half of the list contained 16 targets of each type.

\section{Procedure}

Participants were tested in a single session lasting about $1 \mathrm{~h}$ (including about $30 \mathrm{~min}$ of experimental preparation). Each participant was randomly assigned to one stimulus list and was seated in front of a CRT monitor. Each participant was instructed to read as normally as possible and to try to understand the sentences. Each trial consisted of the following events: A fixation cross appeared in the center of the screen for $700 \mathrm{~ms}$, after which a stimulus sentence was presented in a word-byword manner. Each word appeared in the center of the screen for $650 \mathrm{~ms}$, followed by a blank screen interval of $50 \mathrm{~ms}$. Sentence-ending words appeared with a full stop. A 1450 ms blank-screen interval followed each sentence, after which a prompt appeared asking participants to decide if the preceding sentence was a normal sentence of English. Participants were instructed to answer "Yes" if the sentence was semantically coherent and grammatically well-formed and otherwise "No." Participants responded by pressing one of two buttons, which were counter-balanced (left and right) across participants.

\section{Data acquisition and analysis}

Continuous EEG was recorded using tin electrodes attached to an elastic cap (Electro-cap International) in accordance with the extended 10-20 system (Newer et al., 1998), as illustrated in Fig. 1. Recordings were

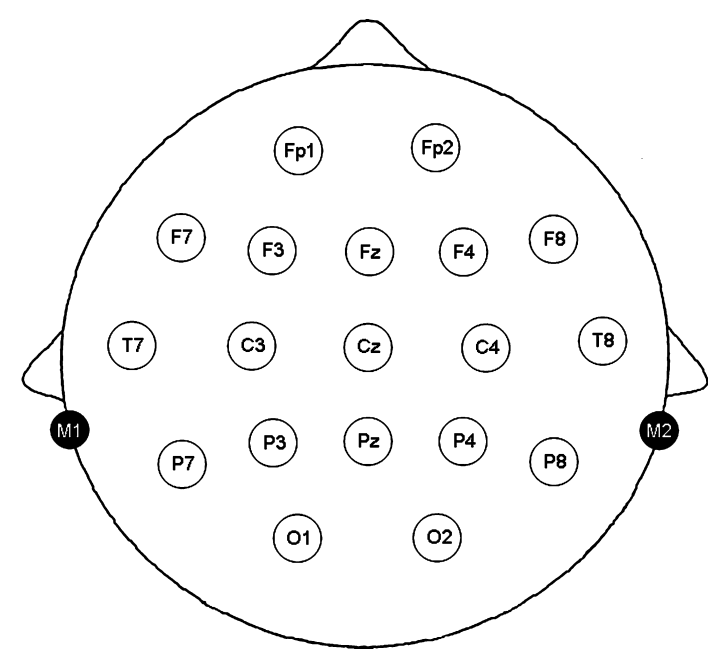

Fig. 1. Nineteen-channel montage used in Experiments 1 and 2. 
obtained from left and right pre-frontal (Fp1, Fp2), frontal $(\mathrm{F} 3, \mathrm{~F} 4)$, inferior frontal $(\mathrm{F} 7, \mathrm{~F} 8)$, temporal (T7, T8), central (C3, C4), parietal (P3, P4), posterior parietal (P7, P8), and occipital (O1, O2) locations, and from three midline locations ( $\mathrm{Fz}, \mathrm{Cz}$, and $\mathrm{Pz})$. Vertical eye movements and blinks were monitored by means of two electrodes, one placed beneath the left eye and one placed to the right of the right eye. The above 19 channels were referenced to an electrode placed over the left mastoid bone and were amplified with a bandpass of $0.01-100 \mathrm{~Hz}$ ( $3 \mathrm{db}$ cutoff) by an SAI bioamplifier system. Activity over the right mastoid was actively recorded on a 20th channel to determine if there were any effects of the experimental variables on the mastoid recordings. No such effects were observed.

Continuous analog-to-digital conversion of the EEG and stimulus trigger codes was performed at a sampling frequency of $200 \mathrm{~Hz}$. ERPs, time-locked to the onset of the target stimulus, were averaged off-line within each sentence type (Violation, Passive Control, and Active Control) for each subject at each electrode site. Grand averages were formed by averaging over participants. Trials characterized by eye blinks, excessive muscle artifact, or amplifier blocking were not included in the average; 8,9 , and $8 \%$ of the trials were removed due to artifact for the Violation, Passive Control, and Active Control stimuli, respectively.

ERP components of interest were quantified by computer as mean voltage within a window of activity. After visual inspection of the data, the following windows were employed: $50-150 \mathrm{~ms}$ (N1), $150-300 \mathrm{~ms}$ (P2), $400-600 \mathrm{~ms}$ (N400), and 600-900 ms (P600), relative to a $100-\mathrm{ms}$ prestimulus window. Repeated measures analyses of variance (ANOVAs) were performed on the above dependent measures. The Greenhouse and Geisser (1959) correction for inhomogeneity of variance was applied to all repeated measures with greater than one degree of freedom in the numerator. In such cases, the corrected $p$ value is reported. Data acquired at midline, medial-lateral, and lateral-lateral sites were treated separately to allow for quantitative analysis of hemispheric differences. On the data from midline sites, two-way ANOVAs were performed, with repeated measures on three levels of stimulus type (Violation, Passive Control, and Active Control) and three levels of electrode position (frontal, central, and parietal). On the data from medial-lateral electrode sites, three-way ANOVAs were performed on three levels of sentence type, two levels of hemisphere (left, right), and five levels of electrode position (pre-frontal, frontal, central, parietal, and occipital). A three-way ANOVA model was also used for analysis of lateral-lateral sites, with repeated measures on three levels of sentence type, two levels of hemisphere, and three levels of electrode position (inferior frontal, temporal, and posterior parietal). Signifi- cant main effects were followed by simple effects analysis.

\section{Results}

\section{Acceptability judgments}

Participants judged the stimuli to be acceptable at the following rates: Violation, $2 \%$; syntactically or semantically anomalous fillers, $8 \%$; and plausible, well-formed stimuli (controls or fillers), 91\%. For all of the stimuli together, participants agreed with the intended acceptability judgments at a mean rate of $92 \%$, with individual participants ranging from 82 to $98 \%$.

\section{ERPS}

Grand-average ERPs to the critical verbs in each sentence type are shown in Fig. 2. Fig. 2A compares the Violation condition to the Passive Control condition, and Fig. 2B compares the Violation condition to the Active Control condition. In these and all subsequent figures, the general shapes of the waveforms are consistent with previously reported data (e.g., Osterhout \& Nicol, 1999). A clear negative-positive complex was visible in the first $300 \mathrm{~ms}$ following word onset (the "N1-P2" complex). These potentials were followed by a negative-going component with a peak around $400 \mathrm{~ms}$ (N400).

Inspection of Fig. 2 shows that the ERP response to the Violation verbs was dominated by a positive deflection, relative to the control conditions, beginning at about $550 \mathrm{~ms}$ after word onset and persisting beyond the end of the epoch. This positive deflection is highly similar to previously reported $\mathrm{P} 600$ responses to syntactic anomalies (cf. Osterhout, McLaughlin, \& Bersick, 1997).

No statistically reliable differences were observed between 50 and $300 \mathrm{~ms}$. In the 400-600 ms window, ANOVAs revealed a marginal effect of stimulus type [midline: $F(2,46)=3.45, p=.05$; medial-lateral: $F(2,46)=2.86$, $p<.1$; and lateral-lateral: $F(2,46)=2.80, p<.1]$. Simple effects analyses at midline sites showed that ERPs to the Active Controls were more negative than those to the Passive Controls $[F(1,23)=4.80, p<.05]$ but that ERPs to Violation stimuli were not different from those elicited by the Passive Controls, $F=2.20$, or Active Controls, $F=2.20$.

In the $600-900 \mathrm{~ms}$ window, a main effect of stimulus type was observed [midline: $F(2,46)=13.16, p<.001$; medial-lateral: $F(2,46)=15.62 ; p<.001$; lateral-lateral: $F(2,46)=15.03, p<.001]$. The effect of stimulus type was largest posteriorly, resulting in an interaction between stimulus type and electrode site [midline, $F(4,92)=5.80$, $p<.005$; medial-lateral, $F(8,184)=5.60, p<.005$; lateral-lateral, $F(4,92)=5.58, p<.005]$. Simple effects analyses showed that ERPs to Violation verbs were more positive-going than those to either control condition [Violation vs. Passive Control: midline, $F(1,23)=18.8$, 
A

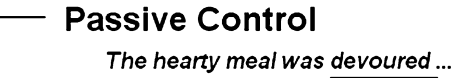

...... Violation

The hearty meal was devouring ...
B
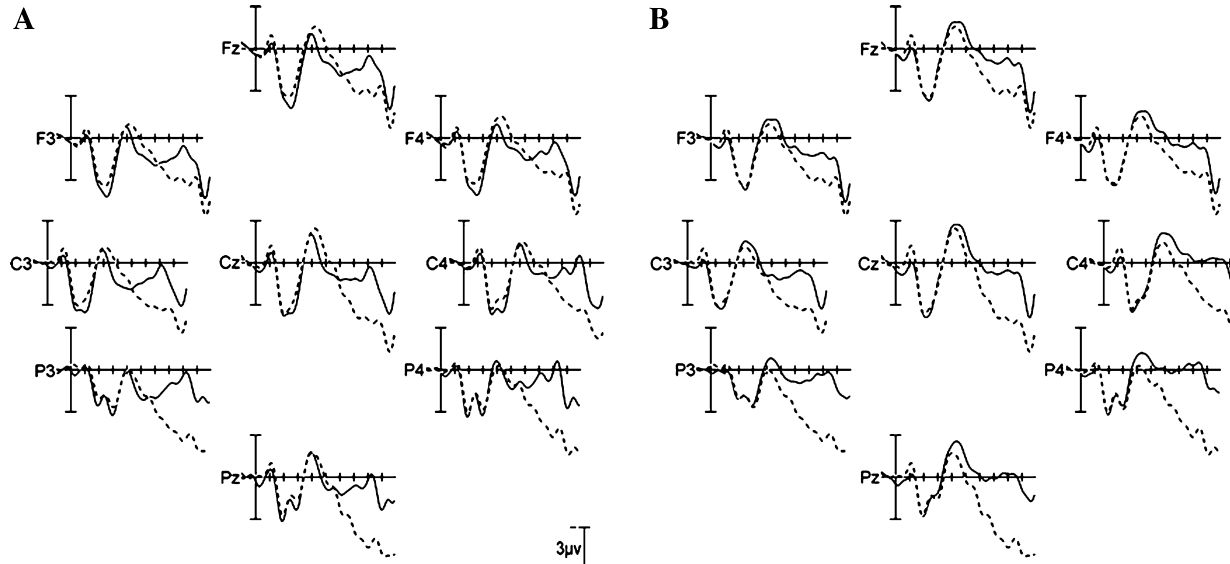

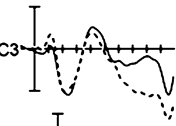

Cz-

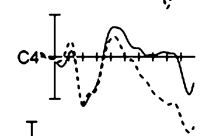
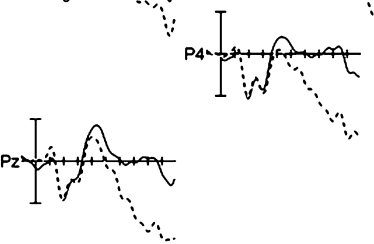

300600900

- Active Control

The hungry boys were devouring ...

...... Violation

The hearty meal was devouring ...

Fig. 2. (A) Grand-average ERPs recorded at three midline sites and six medial-lateral sites to Passive Control verbs (solid line) and Violation verbs (dashed line), Experiment 1. (B) Grand-average ERPs to Active Control verbs (solid line) and Violation verbs (dashed line), Experiment 1. Onset of the critical verbs is indicated by the vertical bar. Each has mark represents $100 \mathrm{~ms}$ of activity. Positive voltage is plotted down.

$p<.001 ;$ medial-lateral, $F(1,23)=22.27, p<.001 ;$ and lateral-lateral, $F(1,23)=25.44, p<.001 ;$ Violation vs. Active Control: midline, $F(1,23)=23.47, p<.001$, medial-lateral, $F(1,23)=28.13, p<.001$; and lateral-lateral, $F(1,23)=23.66, p<.001]$. The control conditions were not different from each other in this time window (midline, medial-lateral, and lateral-lateral, $F \mathrm{~s}<1$ ).

\section{Discussion}

The critical verbs in strings such as The hearty meal was devouring elicited a robust $\mathrm{P} 600$ effect compared to the control conditions, rather than an increase in N400 amplitude. The P600 effect cannot be attributed to an outright syntactic violation, as these stimuli are syntactically well-formed. The absence of an N400 effect suggests that the syntactically supported interpretation (meal as Agent) was not pursued; if it had been, the verb should have been perceived to be semantically anomalous, and should have elicited an N400 effect. The semantic attraction of interpreting meal as Theme of devouring seems to be so compelling that the reader pursues this analysis even when it contradicts the unambiguous syntactic cues in the sentence. This result is inconsistent with syntacto-centric processing models. The result indicates that, at least under some circumstances, semantic processing operates independently of and perhaps even controls syntactic analysis.
We can think of two objections to our conclusions. First, statistical processing accounts (e.g., Hare, McRae, \& Elman, 2004) might argue that the inanimacy of the subject noun (meal) predisposed the comprehension system to assume a passive syntactic analysis before the critical verb was encountered. If so, the critical verb (devouring) would have been perceived to be in the wrong grammatical form, since a passive structure requires the passive participle form (devoured).

Alternatively, a syntax-first processor might assign the anomalous Agent interpretation but detect its implausibility and begin syntactic re-analysis, manifested in the P600 effect. Re-analysis might begin so quickly (Frazier \& Clifton, 1996) that the anomalous Agent interpretation is terminated before an N400 effect is elicited.

We contrasted both of these accounts with our "semantic attraction" hypothesis in Experiment 2 by presenting new sentences such as The dusty tabletops were devouring... Here, the subject noun and critical verb from two different Violation exemplars were combined (e.g., tabletops comes from The dusty tabletops were wiping...). The new pairings caused subject nouns to be anomalous in both Agent and Theme roles for the critical verb (tabletops-devour). If inanimate subject nouns cause early commitments to the passive structure, then they should do so again in Experiment 2; the set of subject nouns is the same. If syntax-first processing causes 
an anomalous Agent interpretation, rapid termination, and syntactic re-analysis, then it should do so again in Experiment 2; the subject nouns were anomalous in the Agent role, as in Experiment 1. Kuperberg et al. (2003) consider a version of the syntax-first account that predicts larger P600 effects in Experiment 2 than Experiment 1 . This account attributes P600 to an attempt to syntactically repair the sentence through re-assignment of thematic roles (e.g., assigning Theme instead of Agent to the pre-verbal noun). Syntactic repair is predicted to be most difficult, and P600 amplitude largest, when it creates implausible interpretations, as in our new sentences (tabletops is an implausible Theme for devour.)

In contrast, a semantic attraction hypothesis predicts a qualitatively new pattern of effects for The dusty tabletops were devouring.... Without semantic attraction to the syntactically unsupported Theme assignment (tabletops is an implausible Theme for devour), no P600 effect is expected. The syntactic cues in the string unambiguously signal the Agent assignment, and this assignment is expected to be pursued. The implausibility of this assignment should cause an increase in N400 amplitude.

Finally, in Experiment 1, a small but significant increase in N400 amplitude was observed for the Active Control condition relative to the Passive Control condition. One possible explanation of this difference is the relative semantic fit between the subject noun and the subsequent main verb; nouns in the Passive Control condition may have been closer semantic associates of the verb (e.g., meal-devour) than were nouns in the Active Control condition (e.g., boys-devour).

\section{Experiment 2}

\section{Method}

\section{Participants}

Twenty-nine undergraduate students (16 females) from the University of Washington participated. None had participated in the first experiment. Ages ranged from 18 to $27($ mean $=20.4)$ years.

\footnotetext{
Stimuli

Ninety-six stimulus items were created, each in three forms: Attraction Violation (2a), Passive Control (2b), and No-Attraction Violation (2d). The full stimulus set is listed in the Appendix A. The Attraction Violation stimuli were identical to the Violation stimuli from Experiment 1. The No-Attraction Violation stimuli were identical in syntactic cues to the Attraction Violations, but the initial noun phrases were now implausible in any thematic role offered by the main verb. The Passive Control sentences were identical to the Passive Control sentences from Experiment 1.
}

2a. The hearty meal was devouring...

Attraction

Violation

$2 \mathrm{~b}$. The hearty meal was devoured ...

Passive

Control

2d. The dusty tabletops were devouring ...

No-Attraction

Violation

No-Attraction Violation exemplars were created by pairing Attraction Violation exemplars (e.g., The hearty meal was devouring by the kids./The dusty tabletops were wiping thoroughly.) and swapping material preceding the critical verb (e.g., The hearty meal was wiping by the kids./The dusty tabletops were devouring thoroughly.). The stimuli were counterbalanced such that a given initial noun phrase or critical verb from any item was seen exactly once by each subject. Furthermore, when parts of a Violation exemplar appeared in two No-Attraction exemplars within the same list, these occurrences were separated by at least 30 trials.

Three stimulus lists were created using these materials. Each participant saw one of these lists. Each list contained 32 stimuli from each condition type. Each stimulus item occurred only once in each list. Stimulus items were rotated through condition assignments, such that each stimulus item occurred in a different condition in each list. Each list also contained 112 filler stimuli. Of these, 20, 20, and 72 were semantically anomalous, syntactically anomalous, and well-formed and plausible, respectively. The proportion of anomalous fillers was lower in Experiment 2 than in Experiment 1. This was done to partially counteract a concomitant increase in the proportion of anomalous target stimuli, which resulted from the removal of well-formed Active Controls and introduction of anomalous No-Attraction Violations to the design. Thus, each list contained 208 sentences. Fifty percent were well-formed and 50\% were anomalous. Fillers and Targets were pseudorandomly ordered, as in Experiment 1.

\section{Procedure}

All procedures were the same as in Experiment 1.

\section{Data acquisition and analysis}

Data acquisition was the same as in Experiment 1. Data analysis was also the same as in Experiment 1, except that the stimulus-type variable now had the following three levels: Attraction Violation, No-Attraction Violation, and Passive Control. Approximately 12, 9, and $9 \%$ of the trials were removed due to artifact for the Attraction Violation, No-Attraction Violation, and Passive Control stimuli, respectively.

\section{Results}

\section{Acceptability judgments}

Participants judged the stimuli to be acceptable at the following rates: Attraction Violation, 3\%; No-Attrac- 
tion Violation, 6\%; syntactically or semantically anomalous fillers, 9\%; and well-formed, plausible stimuli (Passive Control or fillers), 92\%. For all of the stimuli together, participants agreed with the intended acceptability judgments at a mean rate of $94 \%$, with individual participants ranging from 82 to $99 \%$.

\section{ERPs}

Grand-average ERPs to the critical verbs are shown in Fig. 3. Fig. 3A compares the Attraction Violation condition to the Passive Control condition. Fig. 3B compares the No-Attraction Violation condition to the Passive Control condition. In both figures, a clear negative-positive complex was visible in the first $300 \mathrm{~ms}$ following word onset. These potentials were followed by a negative-going component with a peak around $400 \mathrm{~ms}$ (N400).

Inspection of Fig. 3A shows that, as in Experiment 1, Attraction Violation verbs elicited a positive deflection of ERPs, relative to the Passive Control, beginning around $600 \mathrm{~ms}$ after word onset and lasting beyond the end of the epoch. Fig. 3B shows that No-Attraction Violation verbs elicited no positive deflection, but did elicit a negative deflection, beginning at around $400 \mathrm{~ms}$ after word onset and persisting for approximately 200 $400 \mathrm{~ms}$, depending on the electrode site.

As in Experiment 1, no statistically reliable differences were observed between 50 and $300 \mathrm{~ms}$. In the 400-600 ms window, ANOVA revealed a main effect of stimulus type [midline, $F(2,56)=3.55, p<.05$; medial-lateral, $F(2,56)=3.49, p<.05$; and lateral-lateral, $F(2,56)=2.41, p=.11]$. Simple effects analyses showed that ERPs to No-Attraction Violation verbs were more negative than those to both Passive Control and Attraction Violation verbs [No-Attraction Violation vs. Passive Control: midline, $F(1,28)=6.06, p<.05$; medial-lateral, $F(1,28)=3.36, p<.1 ;$ No-Attraction Violation vs. Violation: midline $F(1,28)=4.52, p<.05$; medial-lateral, $F(1,28)=5.73, p<.05]^{4}$ ERPs to the Attraction Viola-

\footnotetext{
${ }^{4}$ A reviewer questioned whether this N400 effect might best be identified as a LAN effect, which is sometimes seen in the response to syntactic anomalies. Descriptively, the N400 label is clearly appropriate as the effect is a modulation of a welldefined negative component that peaks at about $400 \mathrm{~ms}$. With respect to the LAN-N400 distinction, the effect we report here has a central distribution typical of the N400 effect, rather than the anterior distribution that is strongly characteristic of the LAN effect. Furthermore, recent experiments using procedures highly similar to those used here have found no evidence of a LAN effect to anomalies involving inflectional morphology (Allen, Badecker, \& Osterhout, 2003; Osterhout et al., 2002; Osterhout \& Nicol, 1999); nor was a LAN effect observed in Experiment 1. Finally, in sentence-processing studies that do report a LAN effect, the LAN effect is almost always followed by a P600 effect. All of these considerations support our identification of this effect as a modulation of the N400 component.
}

tion verbs were no different from those to Passive Controls [midline, medial-lateral, and lateral-lateral: $F(1,28)<1.5]^{5}$

At non-midline sites, the effect in this window was concentrated in the left hemisphere, as indicated by an interaction between stimulus type and hemisphere [medial-lateral: $\quad F(2,56)=7.60, \quad p<.001$, lateral-lateral: $F(2,56)=6.08, p<.01]$. Simple effects showed that the effect of stimulus type was significant in the left hemisphere but not the right [Left: medial-lateral, $F(2,56)=5.52, p<.01$, lateral-lateral, $F(2,56)=6.02$, $p<.005$; Right: medial-lateral, $F(2,56)=1.92$; laterallateral, $F(2,56)=1.53$.

In the 600-900 ms window, ANOVA revealed a main effect of stimulus type [midline, $F(2,56)=7.23, p<.005$, medial-lateral: $F(2,56)=8.91,, p<.001$; and lateral-lateral, $F(2,56)=9.22, p<.001]$. The effect of stimulus type was largest posteriorly, although not so robustly as in Experiment 1 [stimulus type $\times$ electrode site: midline, $F(4,112)=2.73, \quad p=.05$; medial-lateral, $F(8,224)=$ $1.90, p=.1$; lateral-lateral, $F(4,112)=3.15, p<.05]$. Simple effects analyses revealed that ERPs to Attraction Violation verbs were more positive-going than those to either Passive Control or No-Attraction Violation verbs [Attraction Violation vs. Passive Control: midline, $F(1$, $28)=12.74, \quad p<.01$, medial-lateral, $F(1,28)=11.72$, $p<.01$; lateral-lateral, $F(1,28)=13.60, p<.001 ;$ Attraction Violation vs. No-Attraction Violation: midline, $F(1,28)=8.23, p<.01$; medial-lateral, $F(1,28)=11.61$, $p<.01$; and lateral-lateral, $F(1,28)=7.53, p<.05]$. ERPs to No-Attraction Violation verbs were not reliably different from those to Passive Control verbs (midline, medial-lateral, $F_{\mathrm{S}}<1$, lateral-lateral, $p>.1$ ).

\section{Discussion}

Attraction Violation verbs (e.g., the hearty meal was devouring...) elicited a P600 effect but not an N400 effect, replicating the result of Experiment 1. In contrast, No-Attraction Violation verbs (e.g., the dusty tabletops were devouring...) elicited an N400 effect but not a P600 effect, relative to the same Passive Control stimuli.

Our results were qualitatively modulated by the semantic attractiveness of particular predicate-argument combinations. In the Attraction Violation condi-

\footnotetext{
5 In Experiments 1 and 2, critical verbs elicited a slightly larger N400 in the Violation Attraction condition than in the Passive Control condition. Although this effect was not statistically robust within the $400-600 \mathrm{~ms}$ window, we performed one-way ANOVAs on $50 \mathrm{~ms}$ windows surrounding the regions of largest differences, for midline sites. These differences were not statistically robust [Experiment 1: 400-450 ms, $F(1,23)=1.35, p>.2,450-500 \mathrm{~ms}, \quad F(1,23)=3.70, p=.07$; Experiment 2: $380-430 \mathrm{~ms}, F(1,28)=.52, p>.4]$.
} 
A

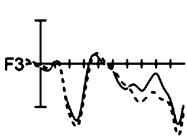

(1)

(1)

(3)

P3,

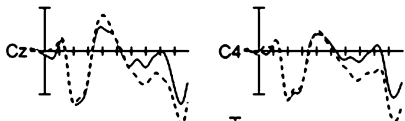

Pand
B

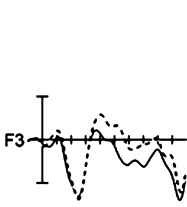

:
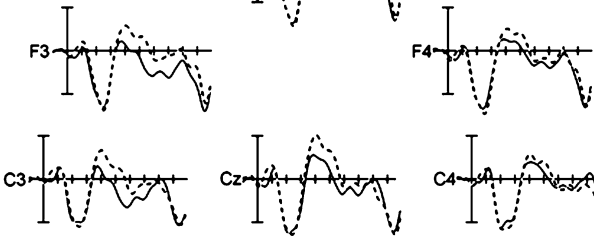

I
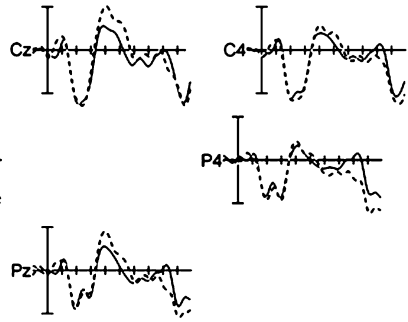

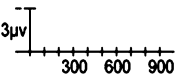

Passive Control

The hearty meal was devoured..

Attraction Violation

The hearty meal was devouring...
- Passive Control

The hearty meal was devoured...

..... No-Attraction Violation

The dusty tabletops were devouring...

Fig. 3. (A) Grand-average ERPs recorded at three midline sites and six medial-lateral sites to Passive Control verbs (solid line) and Attraction Violation verbs (dashed line), Experiment 2. (B) Grand Average ERPs recorded at three midline sites and six medial-lateral sites to Passive Control verbs (solid line) and No-Attraction Violation verbs (dashed line), Experiment 2.

tion, there is a strong semantic attraction to a syntactically unsupported Theme assignment. Commitment to this assignment and the resulting syntactic processing difficulty explains the P600 effect. In the No-Attraction Violation condition, there is no semantic attraction to either of the critical verb's thematic roles (both assignments are implausible). Commitment to the semantically anomalous Agent assignment, guided by syntactic cues, explains the N400 effect.

The P600 effect to Attraction Violations here and in Experiment 1 cannot be explained in terms of early commitments to a passive structural analysis caused by the inanimacy of the initial noun phrase, the auxiliary verb, or some combination of the two. The No-Attraction Violations began with the same noun phrases and auxiliary verbs. The only difference was in the critical verb and other material that followed. Thus, the striking difference between ERPs to Attraction Violations and No-Attraction Violations cannot be explained without some account of the combinatory processing involving the critical verb and the initial noun. For similar reasons, syntax-first models cannot account for the difference in brain responses to Attraction Violations and No-Attraction Violations. Syntax-first accounts might attribute the P600 effect in Attraction Violations to rapid syntactic re-analysis. However, such an account would then inaccurately predict the same effect or a larger one (Kuperberg et al., 2003) in No-Attraction Violations.

\section{General discussion}

It seems to be nearly universally assumed that syntactic cues determine combinatory analysis, when those cues are unambiguous. We report here, however, that the semantic attractiveness of certain predicate-argument combinations is so compelling that it dominates combinatory analysis, overwhelming unambiguous syntactic cues. This conclusion is supported by the results of two experiments in which we recorded brain activity elicited by strings such as The hearty meal was devouring... The syntactic cues in this string unambiguously signal that devour should assign an Agent role to meal. Such an interpretation would render the verb semantically anomalous. However, meal is a semantically compelling Theme for devour. The semantically attractive interpretation can be accommodated by assuming that the verb required the passive -ED suffix rather than the active -ING suffix - that is, by assuming that the verb was in the wrong grammatical form. We observed that verbs such as devouring in these sentences elicit a P600 effect (indicating a perceived syntactic anomaly) rather than an N400 effect. Apparently, the semantic attraction between a predicate and an argument can be so compelling that readers perceive a syntactically well-formed string to be syntactically ill-formed. Experiment 2 demonstrated that this finding was not due to the inanimacy of the subject noun and in fact requires a semantic attraction. 


\section{Related ERP findings}

Kolk et al. (2003) and Kuperberg et al. (2003) both reported P600 effects to verbs that were seemingly semantically anomalous (e.g., The eggs would eat...) (see also Hoeks, Stowe, \& Doedens, 2004). As in our Attraction Violation stimuli, the semantic cues in these sentences support a Theme assignment at the critical verb, whereas the syntactic cues support an implausible Agent assignment. The P600 effects might therefore be attributed to syntactic breakdown when syntactic cues fail to support the attractive Theme assignment. These findings are suggestive but complicated. The stimuli used by Kuperberg et al. (2003) were a mixture of some resembling our Attraction Violations and others resembling our No-Attraction Violations (e.g., the rings finally kissed). This variation may explain the fact that their P600 effect was small in amplitude and accompanied by a small N400 effect. The Kolk et al. (2003) study included a condition resembling our No-Attraction Violations (called "selectional restriction" violations). This condition elicited an N400 effect. Confusingly, however, the condition also elicited a robust P600 effect in the first of their two studies and none in the second. The Kolk et al. (2003) results are further complicated by the placement of the critical verbs inside complex linguistic structures. It is possible that the antecedents of positivities in such situations are different from that in simpler situations, perhaps due to the processing demands of maintaining complex syntactic structures in memory (cf. Kaan et al., 2000). Our study manipulated the presence or absence of semantic attraction to ungrammatical interpretations, using syntactically simple stimuli, and found a qualitative modulation of brain responses to the anomalous verbs (from P600 to N400). This finding suggests a unification of the prior findings with our own by an account based on semantic attraction to an ungrammatical interpretation.

\section{Models of sentence processing}

Our data appear to be consistent with a system of parallel, independent syntactic and semantic processing mechanisms. Semantic processing commits to highly attractive predicate-argument combinations, even when they contradict unambiguous syntactic cues. This is not simply a matter of ignoring syntactic cues, however, as the resulting $\mathrm{P} 600$ effect indicates that the participants were syntactically analyzing the sentence and finding it to be syntactically ill-formed.

Historically, a number of models of syntactic ambiguity resolution have included elements of parallelism in syntactic and semantic processing (Altmann \& Steedman, 1988; Boland, 1997; Frazier, 1987; Rayner et al., 1983; Trueswell et al., 1994). However, most of these models explicitly restrict the independence of semantic processing, so that it is either slower than syntactic analysis and therefore unable to determine initial combinatory commitments (Frazier, 1987; Rayner et al., 1983) or only capable of pursuing grammatically legal analyses (Altmann \& Steedman, 1988; Boland, 1997). Our results strongly conflict with such restrictions on semantic processing. Some of these models are, in principle, free of such restrictions (e.g., Trueswell et al., 1994). However, even in such cases, explicit predictions have focused exclusively on garden path situations. Combinatory language processing is characterized as a series of choices about syntactic analyses. Semantic constraints influence syntactic choices when syntactic cues are ambiguous. However, when syntactic cues are unambiguous, they control combinatory language processing. This syntacto-centric assumption limits the independence of combinatory semantic processing and conflicts with our results.

Recent proposals by Ferreira, Bailey, and Ferraro (2002) and Kamide et al. (2003) allow greater independence for semantic processing. Ferreira et al. (2002) propose that combinatory interpretation is served by "good-enough" heuristics. One heuristic combines the words of a sentence in the manner most consistent with world knowledge. A second treats all Noun-Verb-Noun (NVN) sequences as Agent-Predicate-Theme sequences (Bever, 1970; Carlson \& Tanenhaus, 1988). These heuristics sometimes determine interpretation instead of syntactic analysis. ${ }^{6}$ Consistent with this proposal, numerous studies have shown that plausibility and NVN strategies influence post-sentence measures of language comprehension in syntactically unambiguous sentences (Caplan et al., 1994; Ferreira, 2003; Herriot, 1969; Saffran et al., 1998; Slobin, 1966). Other studies have reported that asyntactic aphasics depend on plausibility and NVN heuristics for comprehension abilities preserved in brain damage (Caramazza \& Zurif, 1976; Grodzinsky, 2000; Saffran et al., 1998). Our findings provide on-line evidence of a process that might be understood as a kind of semantic "heuristic."

Kamide et al. (2003; see also Altmann, 1999; Altmann and Kamide, 1999; Boland et al., 1995) propose that world knowledge allows combinatory semantic processing to predict upcoming linguistic input, using semantic constraints imposed by the input already encountered. This proposal appears consistent with head-mounted eye-tracking studies showing "anticipatory" interpretation (Kamide et al., 2003) as well as lexical

\footnotetext{
6 Townsend and Bever (2001) propose a model that is similar in many respects. However, their proposal attributes algorithmic syntactic analysis to a late stage of analysis, which follows the operation of other more heuristic processes. Although our data might be accommodated within such 'syntax-last' account, they do not require that syntactic processing is last; rather they require that it is not first.
} 
priming studies in which briefly presented verbs speeded the recognition of typical Agents, Patients, and Instruments (Ferretti, McRae, \& Hatherell, 2001). Our results appear consistent with such a proposal.

Our data suggest refinements to these proposals. Ferreira (2003) argues that the NVN heuristic is more influential than the plausibility heuristic, when the two compete for influence. Contrary to this argument, we found that semantic cues favoring a Theme-first analysis determined thematic role assignments even when an NVN heuristic and syntactic cues both signaled an Agent-first analysis, as in our Attraction Violation stimuli.

Kamide et al.'s (2003) proposal does not preclude the possibility that the influence of world knowledge on sentence processing must respect syntactic constraints, for instance verb-specific syntactic knowledge that predicts post-verbal arguments. However, our data show clearly that combinatory semantic processing can operate independently of syntactic constraints; semantic commitments can contradict clear syntactic cues.

\section{Syntactic and semantic streams of processing: Attraction, independence, and interaction}

We suggest here that the proposal of Trueswell et al. (1994; see also Trueswell and Tanenhaus, 1994), while excessively focused on syntactic ambiguity, introduces ideas that are valuable in understanding our findings. The proposal focuses on similarities between the language processing system and the visual processing system, which is widely understood to contain multiple parallel streams of processing (e.g., dorsal and ventral streams that process object and spatial vision, respectively; Ungerleider \& Haxby, 1994). These processing streams are thought to be independent in some respects (each processes a distinct aspect of the visual world) and interactive in others (crosstalk occurs between the multiple streams). Analogously, combinatory language processing might be divided into two independent but constantly interacting streams of analysis. Each stream processes a different dimension of the linguistic input (e.g., syntactic cues and semantic/thematic cues). Each dimension of linguistic input is characterized by pervasive local indeterminacies that can often be resolved by appeal to correlated information from the others.

To accommodate our data, this proposal must expand beyond the exclusive focus on syntactic ambiguity to allow an account of how semantic processing can pursue ungrammatical interpretations. But an expanded parallel model, with truly independent syntactic and semantic subsystems, must reconcile the functional independence of subsystems with interactions between them. That is, how can subsystems be independent of each other even as they influence each other? Here we suggest that the functional independence of syntactic and semantic systems is rooted in the existence of systemspecific forms of attraction (e.g., Tabor \& Tanenhaus, 1999). Each system recognizes attractive analyses. Strongly attractive analyses engender such certainty that they are pursued in the face of countervailing inputs from the other stream. When a system lacks a strongly attractive analysis, it becomes susceptible to the influences of other knowledge sources, which impinge upon it constantly. For the semantic system, strong attraction occurs when one thematic role assignment is far more plausible than any other logically possible assignment. Weak attraction is exemplified in the classic descriptions of the function of syntax (e.g., John attacked Bob vs. John was attacked by Bob). For the syntactic system, strong attraction occurs when unambiguous cues (e.g., morphological inflection) or strong statistical cues make one analysis far more likely than any other. Weak attraction is exemplified in the situations widely studied by models of semantic ambiguity resolution. Viewed this way, there is no inconsistency in the simultaneous proposal of functional independence and constant interaction.

\section{Conclusions and future work}

Our findings demonstrate that, at least under certain conditions, semantic attraction to particular predicateargument combinations determines combinatory processing, even when these combinations contradict unambiguous syntactic cues in the sentence. This provides strong support for a model in which semantic processing can operate independently of syntactic control, and also points to the basis of semantic independence, semantic attraction. But the result raises the question of why semantic attraction "wins" the conflict of cues manifested in our stimuli, in which syntactic cues were also strong, not weak or ambiguous. Our model does not explain this. Perhaps strong semantic attraction is strictly more influential than the strongest syntactic cues in determining interpretations. But this leads to questions about what constitutes "strong" semantic attraction. In the current study, we treated semantic attraction as a binary variable, with a P600 effect elicited in situations of strong attraction to ungrammatical interpretations and an N400 effect when no such attraction existed. In reality, however, semantic attraction almost certainly varies continuously. This implies that there should be a "tipping point" at which the semantic attraction is sufficiently strong to control combinatory processing. We are investigating this issue by manipulating the strength of the semantic association in a pseudo-continuous fashion, and determining the amount of attraction required to "flip" the brain response from one state (manifested by an N400 effect) to another (manifested by a P600 effect). 
Perhaps the phenomenon here is best understood in terms of the different natures of syntactic and semantic processing, rather than their relative strengths. Semantic attraction may reflect the activation of highly stable representations in world knowledge (e.g., Ferretti et al., 2001; Kamide et al., 2003; McRae, Ferretti, \& Amyote, 1997). Confronted by opposition from stable semantic representations, syntactic processing may find some structures easy to "repair." For example, the semantic attraction in The hearty meal was devouring can be accommodated by simply changing the inflectional morpheme on devour from -ING to -ED. The data of Kolk et al. (2003) and Kuperberg et al. (2003) suggest difficulty with this account, because their stimuli could not be repaired through inflectional change. Perhaps syntactic processing creates "fragile" representations (Ferreira et al., 2002), which collapse without support from semantic interpretations. This syntactic fragility is presumably difficult to observe, because syntactic and semantic processing tend to agree on a single interpretation (indeed, syntactic representations appear stable even when interpretations are quite difficult, as in our No-Attraction Violations and other N400 situations). We are currently investigating these issues with syntactic priming manipulations designed to bolster fragile syntactic representations and systematic manipulations of the ease of syntactic repair (e.g., Difficult: The hearty meal will devour... vs. Easy: The hearty meal was devouring...). Thus, further study of the phenomenon here may reveal not only the independence of semantic processing but also fundamental but poorly understood differences between syntactic and semantic processing.
Given the novelty of these results, there are inevitably limitations and potential objections that apply to them. One possible objection is that we presented the sentences at a relatively slow rate of one word every $700 \mathrm{~ms}$. We did this in order to maximally isolate the brain responses of interest. It is conceivable that this rate, which is far from the typical rate at which sentences are read, might somehow have altered the normal course of comprehension. This seems unlikely, however, as our sentences were unexceptional up until the critical anomalous word, and it is difficult to see how or why the rate of presentation would induce a change in the brain response to the anomalous words. Nonetheless, we are currently replicating these experiments using faster visual presentation of the stimuli and by presenting sentences as continuous natural speech. Regardless of the outcome of these replications, our findings provide a compelling demonstration that, at least under certain conditions, semantics (and not syntax) is "in control" of how words are combined during on-line sentence processing.

\section{Acknowledgments}

We thank Janice Chen, Caitlin Rippey, and Judy McLaughlin for help in preparing and running these experiments. We also thank Gerry Altmann, Martin Pickering, and two anonymous reviewers for comments on an earlier version of this article. This research was supported by National Institute of Deafness and Other Communication Disorders Grants F32DC005756, R01DC01947, and P30DC04661.

\section{Appendix. Experimental stimuli for Experiments 1 and 2}

Stimulus sentences labeled "E1" occurred in Experiment 1. Those labeled "E2" occurred in Experiment 2. The "Violation" stimuli from Experiment 1 are identical to the "Attraction Violation" stimuli from Experiment 2; here we use the latter label.

\begin{tabular}{|c|c|c|c|c|}
\hline \multirow{2}{*}{\multicolumn{2}{|c|}{$\begin{array}{l}\text { 1. The murder had been witnessing by the three bystanders } \\
\text { The murder had been witnessed in the dark. }\end{array}$}} & Attraction Violation & E1 & E2 \\
\hline & & Passive Control & E1 & E2 \\
\hline & The bystanders had been witnessing the crime. & Active Control & E1 & \\
\hline & The unpleasant cough syrup was witnessing in the dark. & No-Attraction Violation & & E2 \\
\hline & Patty's overgrown lawn was mowing the boy next door. & Attraction Violation & E1 & E2 \\
\hline & Patty's overgrown lawn was mowed only last week. & Passive Control & E1 & E2 \\
\hline & Patty's teenage son was mowing the lawn. & Active Control & E1 & \\
\hline & All of her money had been mowing the grass. & No-Attraction Violation & & E2 \\
\hline \multirow[t]{4}{*}{3.} & Three more martinis were ordering by Laurie's sister. & Attraction Violation & E1 & E2 \\
\hline & Three more martinis were ordered repeatedly. & Passive Control & E1 & E2 \\
\hline & The regular customers were ordering quiche, as usual. & Active Control & E1 & \\
\hline & The rough part of the wood was ordering late. & No-Attraction Violation & & E2 \\
\hline & The quality of Karla's work was evaluating frequently. & Attraction Violation & E1 & E2 \\
\hline & The quality of Karla's work was evaluated frequently. & Passive Control & E1 & E2 \\
\hline & The engineers were evaluating the success of the new device. & Active Control & E1 & \\
\hline & The old lady's purse had been evaluating Nelson's idea. & No-Attraction Violation & & E2 \\
\hline & The legal contract had been signing falsely. & Attraction Violation & E1 & E2 \\
\hline & The legal contract had been signed by the family. & Passive Control & E1 & E2 \\
\hline
\end{tabular}


Appendix (continued)

The state's governor had been signing new legislation.

An appointment was signing falsely.

6. The vocabulary list was memorizing well.

The vocabulary list was memorized well.

The medical students were memorizing sample exam questions all night.

The simple coffin was memorizing the lines of the poem.

7. The firewood had been chopping poorly.

The firewood had been chopped by Jen's grandfather.

Jen's grandfather had been chopping the firewood.

Mark's wrinkly shirts were chopping vegetables.

8. Lisa's phone had been disconnecting last month.

Lisa's phone had been disconnected last month.

The electrician had been disconnecting the machine's power source.

Mother Theresa's death was disconnecting the two cables.

9. Wendy's muddy car was washing the boys.

Wendy's muddy car was washed wearily.

Wendy and Harriet were washing the muddy car.

Frank's loan application had been washing the used pencil.

10. The library books had been borrowing the graduate student.

The library books had been borrowed by the graduate student.

Katie and Lara had been borrowing dozens of books about botany from the library.

The tragic mistake was borrowing in a hurry.

11. The dark, underwater cave was exploring by the divers.

The dark, underwater cave was explored by the divers.

The cautious scuba divers were exploring the underwater cave.

The phone bill had been exploring at the zoo.

12. The unpleasant cough syrup was swallowing the boy.

The unpleasant cough syrup was swallowed by the boy.

The huge adult alligator had been swallowing fish by the bucket.

The murder had been swallowing with disgust.

13. The pizza had been delivering once more.

The pizza had been delivered by Antonio himself.

The exhausted messenger had been delivering packages all over town.

A genetic mutation was delivering once more.

14. Frank's loan application had been approving by the bank.

Frank's loan application had been approved anyways.

The board of directors had been approving too many expensive projects.

Wendy's muddy car was approving the boy's request.

15. The cheap products had been manufacturing a Belgian firm.

The cheap products had been manufactured by a Belgian firm.

The auto company had been manufacturing parts in China.

A drawing of the house had been manufacturing at a factory.

16. Their secret conversation had been overhearing by a surprised neighbor.

Their secret conversation had been overheard by a surprised neighbor.

The annoyed resident had been overhearing his neighbor's phone conversations through the wall.

A wet snowball had been overhearing despite the precautions.

17. The rough part of the wood was sanding to perfection.

The rough part of the wood was sanded by the carpenter.

The skillful carpenter was sanding the rough edge of the wood.

Three more martinis were sanding the chair.

18. A package had been receiving by the secretary in the office. A package had been received by the secretary in the office.

The secretary had been receiving flowers all day.

The noises in the attic had been receiving assistance from the government.
Active Control

No-Attraction Violation

Attraction Violation

Passive Control

Active Control

No-Attraction Violation

Attraction Violation

Passive Control

Active Control

No-Attraction Violation

Attraction Violation

Passive Control

Active Control

No-Attraction Violation

Attraction Violation

Passive Control

Active Control

No-Attraction Violation

Attraction Violation

Passive Control

Active Control

No-Attraction Violation

Attraction Violation

Passive Control

Active Control

No-Attraction Violation

Attraction Violation

Passive Control

Active Control

No-Attraction Violation

Attraction Violation

Passive Control

Active Control

No-Attraction Violation

Attraction Violation

Passive Control

Active Control

No-Attraction Violation

Attraction Violation

Passive Control

Active Control

No-Attraction Violation

Attraction Violation

Passive Control

Active Control

No-Attraction Violation

Attraction Violation

Passive Control

Active Control

No-Attraction Violation

Attraction Violation

Passive Control

Active Control

No-Attraction Violation
E1

E1

E1

E1

E1

E2

E1 E2

E1 E2

E1

E1

E2

E2

E1

E2

E1

E1

E2

E2

E1

E1

E1

E1

E1

E2

E2

E2

E2

E2

E1

E1

E1

E1

E1

E2

E1

E1

E1

E1

E1

E1

E1

E2

E1

E1

E1

E1

E2

E1

E2

E1

E1

E2

E2

E1

E1

E1

E2

E1

E1

E2

E2

E2 


\section{Appendix (continued)}

19. The club's rules had been violating Richard.

The club's rules had been violated only twice.

The rebel had been violating the rules.

Thirty pounds of potatoes had been violating only twice.

20. A new medication had been prescribing the physician.

A new medication had been prescribed by the physician.

The new doctor had been prescribing powerful painkillers for Jelena's sore knee.

The portrait of Napoleon had been prescribing with caution.

21. The wheat crops had been harvesting by the local farmers.

The wheat crops had been harvested after the rain.

The local farmers had been harvesting the corn all week.

The elevator button had been harvesting after the rain.

22. The musical piece was composing by Beethoven in 1799 .

The musical piece was composed in a dream.

Ludwig von Beethoven was composing symphonies as a teenager.

The bank had been composing in a dream.

23. The old lady's purse had been snatching a kid.

The old lady's purse had been snatched with speed.

The clever dog had been snatching cookies from the table.

The quality of Karla's work was snatching victory from the jaws of defeat.

24. Olson's bulging suitcase had been packing his assistant.

Olson's bulging suitcase had been packed for the trip.

The excited vacationers had been packing their suitcases when the hurricane hit.

Stormy weather had been packing for the trip.

25. Several spelling errors were noticing the careful editor.

Several spelling errors were noticed by the careful editor.

Brittany's close friends were noticing changes in her personality.

The final destination had been noticing too late.

26. An illegal weapon had been smuggling only once.

An illegal weapon had been smuggled only once.

The drug dealer had been smuggling heroin into Canada.

Cleopatra's beauty was smuggling only once.

27. The leftover food was discarding wastefully.

The leftover food was discarded wastefully.

The campers were discarding the leftover food.

The sleek new building was discarding wastefully.

28. Thirty pounds of potatoes had been peeling by the cooks.

Thirty pounds of potatoes had been peeled carefully.

The bored looking cooks had been peeling potatoes for hours.

The club's rules had been peeling the sticker off the box.

29. The grimy pots and pans had been scrubbing the dishwashers.

The grimy pots and pans had been scrubbed by the dishwashers.

The guys in the kitchen had been scrubbing the pots and pans.

The stolen artwork had been scrubbing with vigor.

30. The roast lamb had been carving by a servant.

The roast lamb had been carved by a servant.

The butcher had been carving the meat.

Janet's houseplants were carving before dinner.

31. Cleopatra's beauty was admiring many people.

Cleopatra's beauty was admired always.

The men were admiring the beautiful woman from a distance.

An illegal weapon had been admiring always.

32. A wet snowball had been tossing by the girls through the window.

A wet snowball had been tossed in anger.

The baseball players had been tossing the ball around the infield.

Their secret conversation had been tossing a steak on the grill.
Attraction Violation

Passive Control

Active Control

No-Attraction Violation

Attraction Violation

Passive Control

Active Control

No-Attraction Violation

Attraction Violation

Passive Control

Active Control

No-Attraction Violation

Attraction Violation

Passive Control

Active Control

No-Attraction Violation

Attraction Violation

Passive Control

Active Control

No-Attraction Violation

Attraction Violation

Passive Control

Active Control

No-Attraction Violation

Attraction Violation

Passive Control

Active Control

No-Attraction Violation

Attraction Violation

Passive Control

Active Control

No-Attraction Violation

Attraction Violation

Passive Control

Active Control

No-Attraction Violation

Attraction Violation

Passive Control

Active Control

No-Attraction Violation

Attraction Violation

Passive Control

Active Control

No-Attraction Violation

Attraction Violation

Passive Control

Active Control

No-Attraction Violation

Attraction Violation

Passive Control

Active Control

No-Attraction Violation

Attraction Violation

Passive Control

Active Control

No-Attraction Violation
E1 E2

E1 E2

E1

E1

E2

E2

E1 E2

E1

E2

E1 E2

E1 E2

E1

E1 E2

E1 E2

E1

E2

E1 E2

E1

E2

E1

E2

E1

E1

E1

E1

E1

E1

E1

E1

E1

E1

E2

E1

E1

E2

E1

E2

E2

E1

E1

E2

E2

E1

E2

E1

E2

E1

E1

E2

E2

E1

E1

E2

E2

E2

E1

E1

E1

E2

E2

E1

E2

E1

E2 


\section{Appendix (continued)}

33. The sealed envelope was opening the judge.

The sealed envelope was opened without permission.

Tuxedoed waiters were opening bottles of champagne for the toast.

The men's faces had been opening without permission.

34. The man's beard had been shaving twice a day.

The man's beard had been shaved twice a day.

His uncle Ralph had been shaving his beard off.

The popular amusement park is shaving twice a day.

35. The elevator button had been pressing slowly.

The elevator button had been pressed by the attendant.

The attendant had been pressing the buttons.

The wheat crops had been pressing slowly.

36. The winning lottery numbers had been announcing the TV news.

The winning lottery numbers had been announced by the TV news.

The flight attendant had been announcing the reason for the delay.

The tarnished silverware was announcing on the television.

37. The victim's body had been identifying at the morgue.

The victim's body had been identified by the family members.

The laboratory technicians had been identifying the chemical.

The movie was identifying rare fish for the divers.

38. The hearty meal was devouring by the kids.

The hearty meal was devoured with gusto.

The hungry boys were devouring the plate of cookies when Jack arrived.

The dusty tabletops were devouring with gusto.

39. The overgrown shrubs were trimming regularly.

The overgrown shrubs were trimmed by a gardener.

A gardener was trimming the overgrown shrubbery.

The alarm clock had been trimming regularly.

40. Wilson's unreasonable proposal was rejecting by the boss.

Wilson's unreasonable proposal was rejected at the hospital.

The admissions committee was rejecting nearly every application.

The rare bird's behavior was rejecting all offers.

41. Hathaway's gigantic fortune had been inheriting by his daughters. Hathaway's gigantic fortune had been inherited by his daughters.

Generations of aristocratic Englishmen have been inheriting their fortunes.

The strange mystery had been inheriting the estate from her grandmother.

42. All of her money had been spending before the wedding.

All of her money had been spent before the wedding.

The shopping fanatic had been spending all her money in Bloomingdales.

Patty's overgrown lawn was spending its time on the beach.

43. An appointment was scheduling by the secretary.

An appointment was scheduled by the secretary.

The secretary was scheduling new appointments for the afternoon.

The legal contract had been scheduling for next week.

44. The men's faces had been photographing by a security camera.

The men's faces had been photographed by a security camera.

The intrusive reporter had been photographing the celebrities at the party.

The sealed envelope was photographing at the party.

45. The broken television had been repairing the technician.

The broken television had been repaired by the technician.

The competent technician had been repairing the television.

Larry's note had been repairing the computer's hard drive.

46. The alarm clock had been unplugging accidentally.

The alarm clock had been unplugged late.

\begin{tabular}{|c|c|c|}
\hline Attraction Violation & E1 & E2 \\
\hline Passive Control & E1 & E2 \\
\hline Active Control & E1 & \\
\hline No-Attraction Violation & & E2 \\
\hline Attraction Violation & E1 & E2 \\
\hline Passive Control & E1 & E2 \\
\hline Active Control & E1 & \\
\hline No-Attraction Violation & & E2 \\
\hline Attraction Violation & E1 & E2 \\
\hline Passive Control & E1 & E2 \\
\hline Active Control & E1 & \\
\hline No-Attraction Violation & & E2 \\
\hline Attraction Violation & E1 & E2 \\
\hline Passive Control & E1 & E2 \\
\hline Active Control & E1 & \\
\hline No-Attraction Violation & & E2 \\
\hline Attraction Violation & E1 & E2 \\
\hline Passive Control & E1 & E2 \\
\hline Active Control & E1 & \\
\hline No-Attraction Violation & & E2 \\
\hline Attraction Violation & E1 & E2 \\
\hline Passive Control & E1 & E2 \\
\hline Active Control & E1 & \\
\hline
\end{tabular}

No-Attraction Violation

Attraction Violation

Passive Control

Active Control

No-Attraction Violation

Attraction Violation

Passive Control

Active Control

No-Attraction Violation

Attraction Violation

Passive Control

Active Control

No-Attraction Violation

Attraction Violation

Passive Control

Active Control

No-Attraction Violation

Attraction Violation

Passive Control

Active Control

No-Attraction Violation

Attraction Violation

Passive Control

Active Control

No-Attraction Violation

Attraction Violation

Passive Control

Active Control

No-Attraction Violation

Attraction Violation

Passive Control E2

E1

E2

E1

E2 
Appendix (continued)

The frantic woman had been unplugging every electrical device in the house.

The overgrown shrubs were unplugging accidentally.

47. The car door had been unlocking late at night.

The car door had been unlocked by the child.

The babysitter had been unlocking the back door.

The Queen's 80th birthday was unlocking late at night.

48. The portrait of Napoleon had been painting by a Dutch artist.

The portrait of Napoleon had been painted by a Dutch artist.

The French Impressionist artists had been painting with a focus on light and color.

A new medication had been painting on Tuesday.

49. The embarrassing allegations had been denying by the mayor.

The embarrassing allegations had been denied by the mayor.

The embarassed mayor had been denying allegations of corruption.

Tamara's birthday gift had been denying the rumor.

50. The noises in the attic had been hearing nightly.

The noises in the attic had been heard by the boys.

The frightened campers had been hearing noises in the woods.

A package had been hearing nightly.

51. The appetizers had been serving before the meal.

The appetizers had been served before the meal.

The waiters had been serving the meal.

The final exams had been serving before the meal.

52. Billy's unruly hair was combing his mother to one side.

Billy's unruly hair was combed by his mother to one side.

The patient barber was combing the boy's hair to one side.

The girl's disease was combing the area for escaped prisoners.

53. A drawing of the house had been sketching again.

A drawing of the house had been sketched again.

An artist in the studio had been sketching the house.

The cheap products had been sketching again.

54. The simple coffin was burying the villagers.

The simple coffin was buried at the church.

The tribal people were burying their dead.

The vocabulary list was burying at the church.

55. The homicide case had been investigating diligently.

The homicide case had been investigated by the FBI.

The FBI agents had been investigating the homicide case for weeks.

Martin's tonsils had been investigating the problem.

56. Mark's wrinkly shirts were ironing by his mother.

Mark's wrinkly shirts were ironed by his mother.

Mark's doting mother was ironing his shirts while he slept.

The firewood had been ironing her dress.

57. An important lesson had been learning in space.

An important lesson had been learned in space.

The children had been learning Spanish.

The bathroom floor had been learning in space.

58. The height of the bookcase was measuring by a carpenter.

The height of the bookcase was measured incorrectly.

The carpenter was measuring the height of the bookcase.

An urgent message had been measuring her heart rate.

59. Several important topics were discussing despite the weather.

Several important topics were discussed by the board of trustees.

The board members were discussing several important topics.

The fresh, warm bread was discussing despite the weather.

60. The dusty tabletops were wiping thoroughly.

The dusty tabletops were wiped thoroughly.

The tired busboy was wiping for hours.

The hearty meal was wiping thoroughly.

Active Control
No-Attraction Violation
Attraction Violation
Passive Control
Active Control
No-Attraction Violation
Attraction Violation
Passive Control
Active Control

No-Attraction Violation

Attraction Violation

Passive Control

Active Control

No-Attraction Violation

Attraction Violation

Passive Control

Active Control

No-Attraction Violation

Attraction Violation

Passive Control

Active Control

No-Attraction Violation

Attraction Violation

Passive Control

Active Control

No-Attraction Violation

Attraction Violation

Passive Control

Active Control

No-Attraction Violation

Attraction Violation

Passive Control

Active Control

No-Attraction Violation

Attraction Violation

Passive Control

Active Control

No-Attraction Violation

Attraction Violation

Passive Control

Active Control

No-Attraction Violation

Attraction Violation

Passive Control

Active Control

No-Attraction Violation

Attraction Violation

Passive Control

Active Control

No-Attraction Violation

Attraction Violation

Passive Control

Active Control

No-Attraction Violation

Attraction Violation

Passive Control

Active Control

No-Attraction Violation
E1

$\begin{array}{ll} & \text { E2 } \\ \text { E1 } & \text { E2 } \\ \text { E1 } & \text { E2 } \\ \text { E1 } & \\ & \text { E2 } \\ \text { E1 } & \text { E2 } \\ \text { E1 } & \text { E2 } \\ \text { E1 } & \end{array}$

E1 E2

E1 E2

E1

E1

E1

E1

E1

E1

E1

E1

E1

E1

E1

E1

E1

E1

E1

E1

E1

E1

E1

E1

E1

E1

E1

E1

E1

E1

E1

E1

E1

E1

E1

E1

E1

E1
E2 


\section{Appendix (continued)}

61. A tiny spy camera was concealing by the agent inside a flowerpot. A tiny spy camera was concealed by the agent inside a flowerpot. The sneaky lawyer was concealing the truth. A faint light was concealing their identity.

62. The fresh, warm bread was slicing by the baker into halves. The fresh, warm bread was sliced with love.

The chef's assistants were slicing the mushrooms for a pie. Several important topics were slicing with love.

63. The tarnished silverware was polishing by the butler. The tarnished silverware was polished by the butler. The thorough butler was polishing the doorknobs. The winning lottery numbers had been polishing his shoes.

64. Poisonous fumes had been inhaling the firefighters. Poisonous fumes had been inhaled by the firefighters. The firefighters had been inhaling the smoke. The man's signature was inhaling during the fire.

65. A genetic mutation was discovering the scientists. A genetic mutation was discovered suddenly.

The excited explorers were discovering ancient artifacts everywhere they looked.

The pizza had been discovering new methods for making dough.

66. The Queen's 80th birthday was celebrating expensively.

The Queen's 80th birthday was celebrated by thousands of people in the streets.

Thousands of excited fans were celebrating the Superbowl victory in the streets.

The car door had been celebrating her promotion.

67. The diagram on the chalkboard had been erasing Mrs. Larson.

The diagram on the chalkboard had been erased by Mrs. Larson.

Mrs. Larson had been erasing the chalkboard.

Food for the homeless had been erasing over and over.

68. The movie was directing Steven Spielberg.

The movie was directed professionally.

Steven Spielberg was directing another blockbuster.

The victim's body had been directing the police.

69. Theresa's birthday gift had been wrapping yesterday.

Theresa's birthday gift had been wrapped yesterday.

Theresa's loving grandmother had been wrapping the presents.

The embarrassing allegations had been wrapping yesterday.

70. The popular amusement park is visiting by millions of tourists eh year.

The popular amusement park is visited daily.

The tourists had been visiting the amusement park in the morning.

The man's beard had been visiting a friend in the hospital.

71. Ten new trees had been planting on dry land.

Ten new trees had been planted by the Forestry Service.

The forestry workers had been planting cedar saplings on the hillside.

The sin had been planting doubt in her mind.

72. Food for the homeless had been donating neighborhood residents.

Food for the homeless had been donated many times.

The wealthy American philanthropist had been donating money to

Romanian orphanages.

The diagram on the chalkboard had been donating blood.

73. The rare bird's behavior was observing by the biologists.

The rare bird's behavior was observed by the biologists.

The excited bird watchers were observing the rare eagle.

Wilson's unreasonable proposal was observing the stars.

74. Stormy weather had been forecasting by the weatherman.

Stormy weather had been forecasted by the weatherman.

The weather service had been forecasting snow for the mountain areas.

Olson's bulging suitcase had been forecasting correctly.

\begin{tabular}{|c|c|c|}
\hline Attraction Violation & E1 & E2 \\
\hline Passive Control & E1 & E2 \\
\hline Active Control & E1 & \\
\hline No-Attraction Violation & & $\mathrm{E}$ \\
\hline Attraction Violation & E1 & $\mathrm{E}$ \\
\hline Passive Control & E1 & $\mathrm{E}$ \\
\hline Active Control & E1 & \\
\hline No-Attraction Violation & & $\mathrm{E}$ \\
\hline Attraction Violation & E1 & $\mathrm{E}$ \\
\hline Passive Control & E1 & $\mathrm{E}$ \\
\hline Active Control & E1 & \\
\hline No-Attraction Violation & & $\mathrm{E}$ \\
\hline Attraction Violation & E1 & $\mathrm{E}$ \\
\hline Passive Control & E1 & $\mathrm{E}$ \\
\hline Active Control & E1 & \\
\hline No-Attraction Violation & & $\mathrm{E}$ \\
\hline Attraction Violation & E1 & $\mathrm{E}$ \\
\hline Passive Control & E1 & $\mathrm{E}$ \\
\hline Active Control & E1 & \\
\hline No-Attraction Violation & & $\mathrm{E}$ \\
\hline Attraction Violation & E1 & $\mathrm{E}$ \\
\hline Passive Control & E1 & $\mathrm{E}$ \\
\hline
\end{tabular}

Active Control

No-Attraction Violation

Attraction Violation

Passive Control

Active Control

No-Attraction Violation

Attraction Violation

Passive Control

Active Control

No-Attraction Violation

Attraction Violation

Passive Control

Active Control

No-Attraction Violation

Attraction Violation

Passive Control

Active Control

No-Attraction Violation

Attraction Violation

Passive Control

Active Control

No-Attraction Violation

Attraction Violation

Passive Control

Active Control

No-Attraction Violation

Attraction Violation

Passive Control

Active Control

No-Attraction Violation

Attraction Violation

Passive Control

Active Control

No-Attraction Violation
E1 


\section{Appendix (continued)}

75. The tragic mistake was regretting by Erika for many years.

The tragic mistake was regretted years later.

Erika was regretting the mistake.

The library books had been regretting their behavior.

76. The stolen artwork had been seizing without warning.

The stolen artwork had been seized by the border police.

The police had been seizing shipments of drugs at the border.

The grimy pots and pans had been seizing without warning.

77. The value of the jewels was estimating the dealer.

The value of the jewels was estimated by the dealer.

The jewel expert was estimating the value of the diamond.

The useful new gadget had been estimating professionally.

78. Larry's note had been scribbling his wife.

Larry's note had been scribbled with haste.

Larry's wife had been scribbling a note to him about dinner plans.

The broken television had been scribbling his thoughts on a napkin.

79. Carrie's morning meeting was canceling as expected.

Carrie's morning meeting was canceled by the boss.

Carrie had been canceling all of her meetings.

The bubblegum had been canceling as expected.

80. The girl's disease was curing a simple treatment.

The girl's disease was cured by a simple treatment.

The foreign doctors were curing hundreds of villagers of malaria.

Billy's unruly hair was curing his cold.

81. Janet's houseplants were watering too much.

Janet's houseplants were watered by her neighbor.

The gardener was watering the plants.

The roast lamb had been watering too much.

82. The useful new gadget had been inventing by a bored waiter.

The useful new gadget had been invented by a bored waiter.

The resourceful engineers had been inventing tiny new devices.

The value of the jewels was inventing the digital computer.

83. The phone bill had been paying his roommate.

The phone bill had been paid quickly.

Juan and Perry had been paying too much for their apartment.

The dark, underwater cave was paying attention to the divers.

84. The man's signature was forging the lawyers.

The man's signature was forged by the lawyers.

The con artists were forging the signatures on checks.

Poisonous fumes had been forging very well.

85. The bank had been robbing two masked men.

The bank had been robbed repeatedly.

The clever burglars had been robbing houses in broad daylight.

The musical piece was robbing repeatedly.

86. An urgent message had been sending by the ambassador to the President.

An urgent message had been sent again.

The Prime Minister had been sending urgent messages to her

Ambassador.

The height of the bookcase was sending mixed signals to the carpenter.

87. The sleek new building was designing a team of German architects.

The sleek new building was designed by a team of German architects.

A team of architects had been designing the new building.

The leftover food was designing with flair.

88. The final exams had been grading in school.

The final exams had been graded in school.

The professor had been grading the final exams until 4 AM.

The appetizers had been grading Iverson's students.

89. The final destination had been reaching too late.

The final destination had been reached too late.

\begin{tabular}{|c|c|c|}
\hline Attraction Violation & E1 & E2 \\
\hline Passive Control & E1 & E2 \\
\hline Active Control & E1 & \\
\hline No-Attraction Violation & & E2 \\
\hline Attraction Violation & E1 & E2 \\
\hline Passive Control & E1 & E2 \\
\hline Active Control & E1 & \\
\hline No-Attraction Violation & & E2 \\
\hline Attraction Violation & E1 & E2 \\
\hline Passive Control & E1 & E2 \\
\hline Active Control & E1 & \\
\hline No-Attraction Violation & & E2 \\
\hline Attraction Violation & E1 & E2 \\
\hline Passive Control & E1 & E2 \\
\hline Active Control & E1 & \\
\hline No-Attraction Violation & & E2 \\
\hline Attraction Violation & E1 & E2 \\
\hline Passive Control & E1 & E2 \\
\hline Active Control & E1 & \\
\hline No-Attraction Violation & & E2 \\
\hline Attraction Violation & E1 & E2 \\
\hline Passive Control & E1 & E2 \\
\hline Active Control & E1 & \\
\hline No-Attraction Violation & & E2 \\
\hline Attraction Violation & E1 & E2 \\
\hline Passive Control & E1 & E2 \\
\hline Active Control & E1 & \\
\hline No-Attraction Violation & & E2 \\
\hline Attraction Violation & E1 & E2 \\
\hline Passive Control & E1 & E2 \\
\hline Active Control & E1 & \\
\hline No-Attraction Violation & & E2 \\
\hline Attraction Violation & E1 & E2 \\
\hline Passive Control & E1 & E2 \\
\hline Active Control & E1 & \\
\hline No-Attraction Violation & & E2 \\
\hline Attraction Violation & E1 & E2 \\
\hline Passive Control & E1 & E2 \\
\hline Active Control & E1 & \\
\hline No-Attraction Violation & & E2 \\
\hline Attraction Violation & E1 & E2 \\
\hline Passive Control & E1 & E2 \\
\hline Active Control & E1 & \\
\hline No-Attraction Violation & & E2 \\
\hline Attraction Violation & E1 & E2 \\
\hline Passive Control & E1 & E2 \\
\hline Active Control & E1 & \\
\hline
\end{tabular}

No-Attraction Violation

Attraction Violation

E1

Passive Control

E1

Active Control

E1

No-Attraction Violation

Attraction Violation

Passive Control

Active Control

No-Attraction Violation

Attraction Violation

Passive Control 


\section{Appendix (continued)}

The curious child had been reaching for the cup on the table. Several spelling errors were reaching too late.

90. A faint light was perceiving by the rescue workers.

A faint light was perceived underwater.

The worried pilot was perceiving a rattling sound in the jet's engine.

A tiny spy camera was perceiving underwater.

91. The bubblegum had been chewing by the boy.

The bubblegum had been chewed by the boy.

The hungry dog had been chewing a bone.

Carrie's morning meeting was chewing for a long time.

92. Martin's tonsils had been removing at the hospital.

Martin's tonsils had been removed at the hospital.

The surgeon had been removing the cancerous growth.

The homicide case had been removing at the hospital.

93. Mother Theresa's death was mourning millions of people.

Mother Theresa's death was mourned by millions of people.

The black-clad women were mourning the death of their brother.

Lisa's phone had been mourning the loss of a loved one.

94. The bathroom floor had been mopping by a janitor.

The bathroom floor had been mopped in the past.

The school janitor had been mopping the bathroom.

An important lesson had been mopping in the past.

95. The sin had been confessing by the repentant Catholic.

The sin had been confessed on Sunday.

The repentant Catholic had been confessing his sins.

Ten new trees had been confessing on Sunday.

96. The strange mystery had been solving the detectives.

The strange mystery had been solved at the station.

The brilliant detective had been solving mysterious crimes for two decades.

Hathaway's gigantic fortune had been solving at the station.
Active Control

No-Attraction Violation

Attraction Violation

Passive Control

Active Control

No-Attraction Violation

Attraction Violation

Passive Control

Active Control

No-Attraction Violation

Attraction Violation

Passive Control

Active Control

No-Attraction Violation

Attraction Violation

Passive Control

Active Control

Attraction Violation

Passive Control

Active Control

No-Attraction Violation

Attraction Violation

Passive Control

Active Control

No-Attraction Violation

Attraction Violation

Passive Control

Active Control
No-Attraction Violation

$\begin{array}{ll}\text { E1 } & \\ \text { E1 } & \text { E2 } \\ \text { E1 } & \text { E2 } \\ \text { E1 } & \\ & \text { E2 } \\ \text { E1 } & \text { E2 } \\ \text { E1 } & \text { E2 } \\ \text { E1 } & \\ & \text { E2 } \\ \text { E1 } & \text { E2 } \\ \text { E1 } & \text { E2 } \\ \text { E1 } & \text { E2 } \\ \text { E1 } & \text { E2 } \\ \text { E1 } & \text { E2 } \\ \text { E1 } & \\ & \text { E2 } \\ \text { E1 } & \text { E2 } \\ \text { E1 } & \text { E2 } \\ \text { E1 } & \text { E2 } \\ \text { E1 } & \text { E2 } \\ \text { E1 } & \text { E2 } \\ \text { E1 } & \\ & \text { E2 } \\ \text { E1 } & \text { E2 } \\ \text { E1 } & \text { E1 } \\ \text { E1 } & \end{array}$

No-Attraction Violation

\section{References}

Allen, M. D., Badecker, W., \& Osterhout, L. (2003). Morphological analysis during sentence processing. Language and Cognitive Processes, 18, 405-430.

Altmann, G. T. M. (1998). Ambiguity in sentence processing. Trends in Cognitive Sciences, 2, 146-152.

Altmann, G. T. M. (1999). Thematic role assignment in context. Journal of Memory and Language, 41, 124-145.

Altmann, G. T. M., \& Kamide, Y. (1999). Incremental interpretation at verbs: restricting the domain of subsequent reference. Cognition, 73, 247-264.

Altmann \& Steedman (1988). Interaction with context during human sentence processing. Cognition, 30, 191-238.

Bever, T. G. (1970). The cognitive basis for linguistic structures. In J. R. Hayes (Ed.), Cognition and the development of language (pp. 279-362). New York: Wiley.

Boland, J. E. (1997). The relationship between syntactic and semantic processes in sentence comprehension. Language and Cognitive Processes, 12, 423-484.

Boland, J. E., Tanenhaus, M. K., Garnsey, S. M., \& Carlson, G. N. (1995). Verb argument structure in parsing and interpretation: Evidence from wh-questions. Journal of Memory and Language, 34, 774-806.
Caplan, D., Hildebrandt, N., \& Waters, G. S. (1994). Interaction of verb selection restrictions, noun animacy and syntactic form in sentence processing. Language and Cognitive Processes, 9, 549-585.

Caramazza, A., \& Zurif, E. G. (1976). Dissociation of algorithmic and heuristic processes in sentence comprehension: Evidence from aphasia. Brain and Language, 3, 572-582.

Carlson, G. N., \& Tanenhaus, M. K. (1988). Thematic roles and language comprehension. In W. Wilkens (Ed.), Syntax and semantics (vol. 21, pp. 263-300). New York: Academic Press.

Clifton, C., Traxler, M. J., Mohamed, M. T., Williams, R. S., Morris, R. K., \& Rayner, K. (2003). The use of thematic role information in parsing: Syntactic processing autonomy revisited. Journal of Memory and Language, 49, 317-334.

Ferreira, F., Bailey, K. G. D., \& Ferraro, V. (2002). Goodenough representations in language comprehension. Current Directions in Psychological Science, 11, 11-15.

Ferreira, F., \& Clifton, C. (1986). The independence of syntactic processing. Journal of Memory and Language, 25, 348-368.

Ferreira, F. (2003). The misinterpretation of noncanonical sentences. Cognitive Psychology, 47, 164-203. 
Ferretti, T. R., McRae, K., \& Hatherell, A. (2001). Integrating verbs, situation schemas, and thematic role concepts. Journal of Memory and Language, 44, 516-547.

Frazier, L. (1987). Sentence processing: A tutorial review. In M. Coltheart (Ed.), Attention and performance XII: The psychology of reading. Hillsdale, NJ: Erlbaum.

Frazier, L., \& Clifton, C. (1996). Construal. Cambridge, MA: MIT Press.

Friederici, A. D. (1995). The time course of syntactic activation during language processing: A model based on neuropsychological and neurophysiological data. Brain \& Language, $62,311-341$.

Greenhouse, S., \& Geisser, S. (1959). On methods in the analysis of profile data. Psychometrika, 24, 95-112.

Grodzinsky, Y. (2000). The neurology of syntax: Language use without Broca's area. Behavioral and Brain Sciences, 23, $1-71$.

Hagoort, P., Brown, C., \& Groothusen, J. (1993). The syntactic positive shift as an ERP measure of syntactic processing. Language and Cognitive Processes, 8, 439-483.

Hare, M., McRae, K., \& Elman, J. (2004). Admitting that admitting verb sense into corpus analyses makes sense. Language and Cognitive Processes, 19, 181-224.

Herriot, P. (1969). The comprehension of active and passive sentences as a function of pragmatic expectations. Journal of Verbal Learning and Verbal Behavior, 8, $166-260$

Hoeks, C. J., Stowe, L. A., \& Doedens, G. (2004). Seeing words in context: the interaction of lexical and sentence level information during reading. Cognitive Brain Research, 19, $59-73$.

Inoue, K., \& Osterhout, L. (2004). Manuscript in preparation.

Kaan, E., Harris, A., Gibson, E., \& Holcomb, P. (2000). The P600 as an index of syntactic intergration difficulty. Language and Cognitive Processes, 15, 159-201.

Kamide, Y., Altmann, G. T. M., \& Haywood, S. (2003). The time-course of prediction in incremental sentence processing: Evidence from anticipatory eye movements. Journal of Memory and Language, 49, 133-156.

Kolk, H. H. J., Chwilla, D. J., van Herten, M., \& Oor, P. J. W. (2003). Structure and limited capacity in verbal working memory: A study with event-related potentials. Brain and Language, 85, 1-36.

Kuperberg, G. R., Sitnikova, T., Caplan, D., \& Holcomb, P. (2003). Electrophysiological distinctions in processing conceptual relationships within simple sentences. Cognitive Brain Research, 17, 117-129.

Kutas, M., \& Hillyard, S. A. (1980). Reading senseless sentences: Brain potentials reflect semantic incongruity. Science, 207, 203-205.

Kutas, M., \& Hillyard, S. A. (1984). Brain potentials reflect word expectancy and semantic association during reading. Nature, 307, 161-163.

MacDonald, M. C., Pearlmutter, N. J., \& Seidenberg, M. S. (1994). Lexical nature of syntactic ambiguity resolution. Psychological Review, 101, 676-703.

McKinnon, R., \& Osterhout, L. (1996). Constraints on movement phenomena in sentence processing: Evidence from event-related brain potentials. Language and Cognitive Processes, 11, 495-523.
McRae, K., Ferretti, T. R., \& Amyote, L. (1997). Thematic roles as verb-specific concepts. Language and Cognitive Processes, 12, 137-176.

Neville, H. J., Nicol, J. L., Barss, A., Forster, K. I., \& Garrett, M. (1991). Syntactically based sentence processing classes: Evidence from event-related brain potentials. Journal of Cognitive Neuroscience, 3, 151-165.

Newer, M. R., Comi, G., Emerson, R., Fuglsang-Frederiksen, A., Guérit, J.-M, Hinrichs, H., et al. (1998). IFCN standards for digital recording of clinical EEG. Electroencephalography and Clinical Neurophysiology, 106, 259-261.

Osterhout, L. (1997). On the brain response to syntactic anomalies: Manipulations of word position and word class reveal individual differences. Brain and Language, 59, 494-522.

Osterhout, L., \& Holcomb, P. J. (1992). Event-related brain potentials elicited by syntactic anomaly. Journal of Memory and Language, 31, 785-806.

Osterhout, L., McLaughlin, J., Allen, M., \& Inoue, K. (2002). Brain potentials elicited by prose-embedded linguistic anomalies. Memory and Cognition, 30, 1304-1312.

Osterhout, L., \& Mobley, L. A. (1995). Event-related brain potentials elicited by failure to agree. Journal of Memory and Language, 34, 739-773.

Osterhout, L., \& Holcomb, P. J. (1993). Event-related potentials and syntactic anomaly: Evidence of anomaly detection during the perception of continuous speech. Language \& Cognitive Processes, 8, 413-438.

Osterhout, L., Holcomb, P. J., \& Swinney, D. A. (1994). Brain potentials elicited by garden-path sentences: Evidence of the application of verb information during parsing. Journal of Experimental Psychology: Learning, Memory, and Cognition, 20, 786-803.

Osterhout, L., McKinnon, R., Bersick, M., \& Corey, V. (1996). On the language-specificity of the brain response to syntactic anomalies: Is the syntactic positive shift a member of the P300 family?. Journal of Cognitive Neuroscience, 8, 507-526.

Osterhout, L., McLaughlin, J., Kim, A., Greenwald, R., \& Inoue, K. (2004). Sentences in the brain: Event-related potentials as real-time reflections of sentence comprehension and language learning. In M. Carreiras \& C. Clifton, Jr. (Eds.), The on-line study of sentence comprehension: Eyetracking, ERP, and beyond. Psychology Press.

Osterhout, L., McLaughlin, J., \& Bersick, M. (1997). Eventrelated brain potentials and human language. Trends in Cognitive Sciences, 1, 203-209.

Osterhout, L., \& Nicol, J. (1999). On the distinctiveness, independence, and time course of the brain responses to syntactic and semantic anomalies. Language and Cognitive Processes, 14, 283-317.

Rayner, K., Carlson, M., \& Frazier, L. (1983). The interaction of syntax and semantics during sentence processing. Journal of Verbal Learning and Verbal Behavior, 22, 358-374.

Saffran, E. M., Schwartz, M. F., \& Linebarger, M. C. (1998). Semantic influences on thematic role assignment: Evidence from normals and aphasics. Brain and Language, 62, 255-297.

Slobin, D. I. (1966). Grammatical transformations and sentence comprehension in childhood and adulthood. Journal of Verbal Learning and Verbal Behavior, 5, 219-227. 
Tabor, W., \& Tanenhaus, M. K. (1999). Dynamical models of sentence processing. Cognitive Science, 23(4), 491-515.

Tanenhaus, M. K., Spivey-Knowlton, M. J., Eberhard, K. M., \& Sedivy, J. C. (1995). Integration of visual and linguistic information in spoken language comprehension. Science, 268, 1632-1634.

Townsend, D. J., \& Bever, T. G. (2001). Sentence comprehension: The integration of habits and rules. Cambridge, MA: MIT Press.

Trueswell, J. C., \& Tanenhaus, M. K. (1994). Toward a lexicalist framework for constraint-based syntactic ambigu- ity resolution. In C. Clifton, K. Rayner, \& L. Frazier (Eds.), Perspectives on sentence processing. Hillsdale, NJ: Lawrence Erlbaum Associates.

Trueswell, J. C., Tanenhaus, M. K., \& Garnsey, S. M. (1994). Semantic influences on parsing: Use of thematic role information in syntactic ambiguity resolution. Journal of Memory and Language, 33, 285-318.

Ungerleider, L. G., \& Haxby, J. V. (1994). 'What' and 'where' in the human brain. Current Opinion in Neurobiology, 4, 157-165. 